\title{
Qualitative Interpretation of Load-Settlement Curves of Bored Piles
}

\section{H. S. Thilakasiri}

\begin{abstract}
Static load testing of piles yield only the load-settlement behaviour of piles. While it is useful to get the load-settlement behaviour, the static load testing yields no other direct information regarding the distribution of load carrying capacity along the pile shaft and at the pile toe. However, various researchers have shown that the shape of the load-settlement curve can be interpreted to get such information. This paper attempts to discuss the reasons for commonly observed variations of the shape of the load-settlement curves obtained by testing bored piles and the use of the Elastic Shortening Line (ESL) in interpretation of the load-settlement curves. Load-settlement curves are categorized using the ESL and a mathematical model, developed to simulate the load-settlement behaviour of piles, is used to investigate the reasons for variation of the shape of the load-settlement curves of different categories. Accuracy of the commonly used Van Weele [8] method to estimate the skin friction from the loadsettlement curve is also discussed.
\end{abstract}

Keywords: Bored piles, Static load Test, Interpretation.

\section{Introduction}

Piles are load tested to obtain information related to load-settlement behaviour, load carrying mechanism, types of material present along the pile shaft and the pile toe, structural integrity of the pile. However, static load testing of piles provide the load-settlement curve, showing the load-settlement response of the pile. Therefore, the geotechnical engineer should interpret the load-settlement information to obtain the other information about the pile. This is especially important for a test pile as the information gathered will be used in designing the other piles. Various researchers (Tomlinson [3], and Van Weele [8]) have shown that the shape of the load-settlement curve of a pile can yield more information than the directly obtained row data related to load-settlement behaviour. More information regarding the pile could be obtained from dynamic load testing of piles using Pile Driving Analyser (PDA). However, interpretation of the results of the PDA test should be carried out by competent engineers and, in most cases, PDA results should also be verified by static load testing of some of the piles tested using PDA. Therefore, the analysis or interpretation of static load test results is extremely important.

In this research, it is aimed at investigating the methods of obtaining more information from load-settlement data obtained from static load testing of bored piles. The tools, that are introduced here to obtain information of the load tested piles, yield qualitative information about the pile rather than the quantitative information. The qualitative information, together with other interpretation techniques presented in Thilakasiri et al. [5] and [6], will provide sufficient amount of information regarding the tested pile. Even though most of the interpretation methods discussed here will be applicable to all the types of piles, the validity of the developed methodologies will be limited to bored piles since they are verified only using load-settlement behaviour of bored piles.

\section{Load transfer Mechanisms of Bored piles}

It is very important to get an understanding about the load transfer mechanism of piles before investigation of the load-settlement behaviour. If the load acting on the pile is increased from zero to the ultimate capacity, following three stages could be identified [1]:

i. During initial stage of loading most of the load carried by the skin friction and less through end bearing and with increase pile penetration the skin friction reaches the ultimate value;

Eng. (Dr.) H.S. Thilakasiri, C. Eng., PEng.(SL). MIE(SL), B.Sc. Eng. (Hons) (Moratuwa), M.Sc. (Lond), PhD(USA), Senior Lecturer in Engineering, Department of Civil Engineering, University of Moratuwa, Sri Lanka. 
ii. During middle stage of the loading, the load capacity is the sum of limiting skin resistance plus the point capacity; and

iii. During final stage, the load-settlement curve reaches vertical asymptote indicating ultimate carrying capacity.

The Figure 1 illustrates the load carried by skin friction and end bearing during loading through the above three stages.

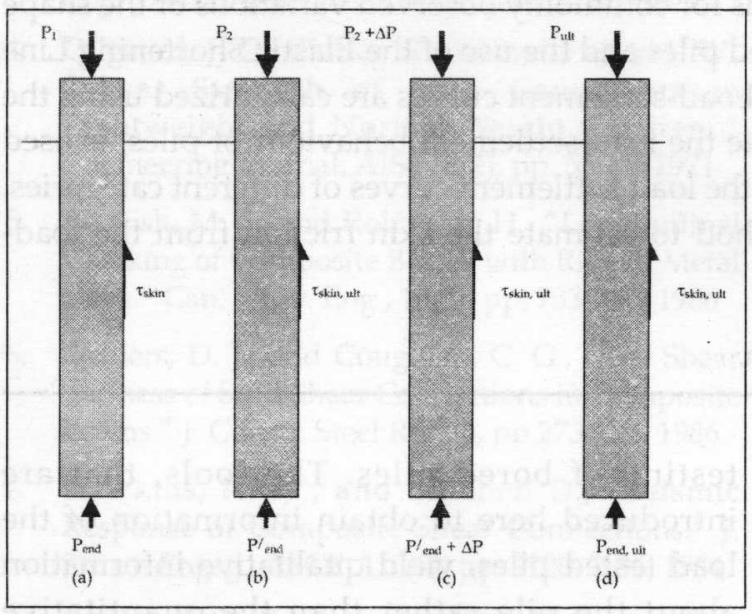

Figure 1: Load carrying through: (a) stage I; (b) end of stage I; (c) stage II and (d) end of stage III

Settlement of the pile may be due to only two reasons: (i) Compression of the pile shaft; and (ii) settlement of the pile at the toe. Since within normal loading conditions, the pile material is stressed within the elastic range the compression of the pile shaft will be the elastic shortening of the pile due to the increment of the axial stress along the pile shaft. However, as the skin friction varies along the pile shaft, the axial stress increment along the pile shaft is not uniform. During stage I, the axial load in the pile decreases with the depth and the elastic compression of the pile, per unit increase in the pile top force, increases with the pile top force. This is mainly due to the increase in the length of the pile involved in carrying the pile top force. At the end of stage II (Figure 1(b)), the elastic compression of the pile, per unit increase in the pile top force, reaches the maximum and during stage II and III (Figure 1(c)\&1(d)) the same rate of elastic compression of the pile continues. The elastic compression of the pile shaft $(\Delta \rho)$, corresponding to an increase of $\Delta \mathrm{P}$ of the pile top force, during stages II \& III can be mathematically represented using the onedimensional Hook's law as given in Equation [1].
$\Delta \rho=\frac{\Delta p L}{A E}$

Where $L, A$, and $E$ are length, cross sectional area and Young's modulus of pile materials respectively. Therefore, during stages II and III, the increase in the settlement of the pile toe due to a loading increment $(\Delta P)$ is the total settlement of the pile at the top minus the elastic compression of the pile shaft given by Equation [1]. During stage I, the elastic compression is less than the amount given by equation [1\} for a given load increment and the difference is governed by the location of the skin friction along the pile shaft and the shear stiffness of the surrounding soil. It is obvious from the above discussion that if the stiffness and the capacity of the pile is to be investigated, it should be done by considering the elastic compression of the pile shaft as the reference line. Therefore, a reference line in the load settlement curve indicating the elastic compression of the pile shaft, acting as a short column without any skin friction, will be a very valuable tool in interpretation of the load-settlement curves obtained from static load testing of piles. This reference line is identified as the 'Elastic Shortening Line' (ESL) and it is mathematically represented by equation [2] in terms of the total force at the pile top $(P)$ and the total settlement $(\rho)$ rather than the incremental values considered in equation [1].

$\rho=\frac{P L}{A E}$

\section{Classification of the load-settlement curves based on the ESL}

Load settlement curves obtained from field testing of bored piles could be categorized in to three groups, as shown in Figures 2 to 4 , based on the location of the ESL with respect to the load-settlement curves obtained. The categories are identified as given below:

Catagorey I - Initial portion of the Loadsettlement curve is above the ESL (Figure 2).

Catagorey II - Initial portion of the loadsettlement curve is parallel to the ESL (Figure 3).

Catagorey III - Initial portion of the loadsettlement curve is below the ESL (Figure 4). 


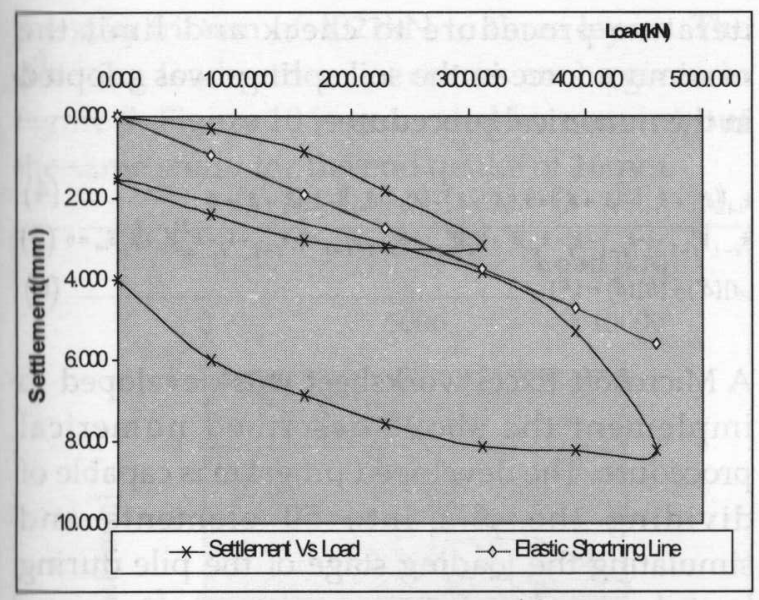

Figure 2: Category I - Initial portion of the Loadsettlement curve is above the ELS

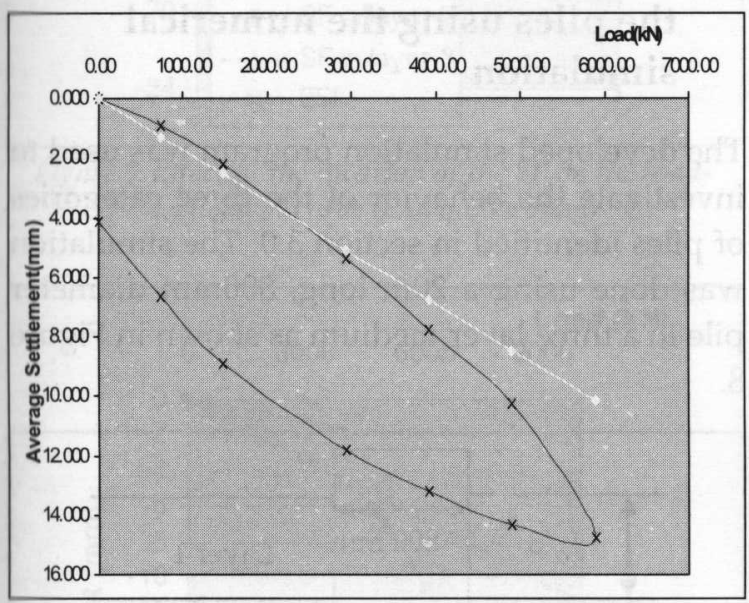

Figure 3: Category II - Initial portion of the loadsettlement curve is parallel to the ESL

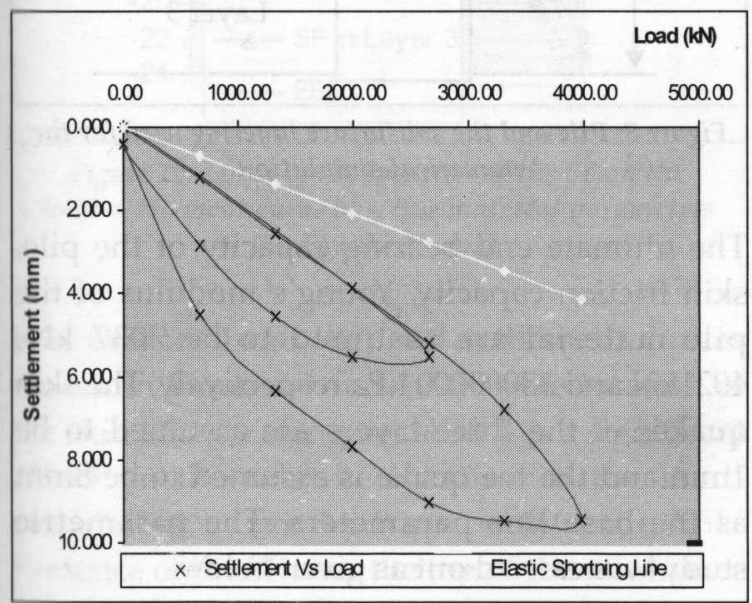

Figure 4:Category III - Initial portion of the loadsettlement curve is below the ES

Investigation of the positions of the loadsettlement curves relative to the ESL will be discussed by simulation of the pile load test as explained in Thilakasiri [7]. A brief description of the simulation method is given below.

\section{Mathematical simulation of the load- settlement behavior of bored piles}

A mathematical simulation presented in Thilakasiri [7] is used to investigate the behavior of the above mentioned categories of piles. In this mathematical simulation, pile is divided into $n$ number of elements and equilibrium of each element is considered after loading. In descritization of the pile, the portion of the pile above the ground surface is considered as a single element and the portion of the pile below the ground surface is divided into $n-1$ number of elements with equal length as shown in Figure 5.

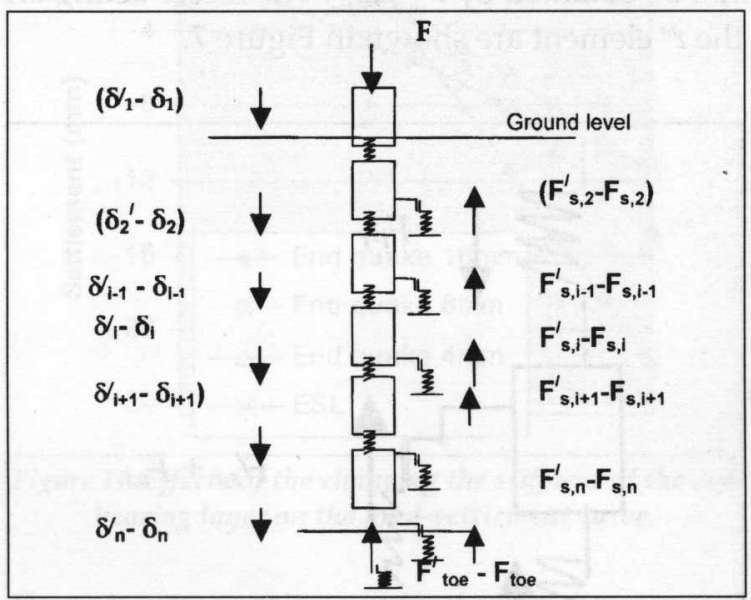

Figure 5: Discritization of the pile with deflection and forces acting on each element.

In Figure $5, \delta_{\mathrm{I}}$ and $\delta / \mathrm{I}$ are previous settlement of the $\mathrm{i}^{\mathrm{t} \text { th }}$ element and the settlement increment of the same element due to increment of the load acting on the pile by $F$ whereas $F_{\mathrm{s}}$ and $F / \mathrm{s}$ are the previous skin friction and the increment in the skin friction due to the same load increment on the pile. The pile elements are connected to each other through pile springs and the skin friction acting on each element is modeled as an elastic-perfectly plastic sliding spring with a maximum resistance of $\mathrm{F}_{\mathrm{us}, \mathrm{i}}$ on the $\mathrm{i}^{\text {th }}$ element as shown in Figure 6.

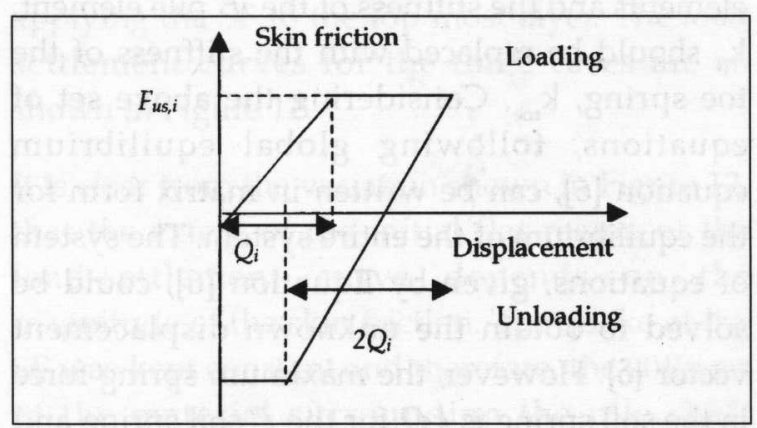

Figure 6: Load deflection behavior of a spring used to model the skin friction on $i^{\text {th }}$ element. 
The maximum elastic deformation of the soil spring $\left(Q_{i}\right)$ is referred to as the quake of the skin friction of the $i^{\text {th }}$ element. Similar elasto-plastic sliding spring can be utilized to model the ground response at the pile toe with maximum force at the pile toe as $\mathrm{F}_{\text {utoe }}$ and the quake at the toe as $\mathrm{Q}_{\text {toe }}$.

The stiffness of the pile spring, $K_{\mathrm{i}^{\prime}}$ connecting $\mathrm{i}^{\text {th }}$ element and the $i+1^{\text {th }}$ element, can be taken as $A_{i} E / \Delta L_{i}$, where $A, E$ and $\Delta L_{i}$ are cross sectional area, Young's modulus and length of the $i^{\text {th }}$ element respectively. The stiffness of the soil spring for the $i^{\text {th }}$ element, $k_{s, i}$ can be obtained from $F_{u s,} / Q_{i}$ and the same for the toe spring, $k_{t o e^{\prime}}$ can be obtained by $F_{u t o o} / Q_{t o e}$. The forces acting on the $i^{\text {th }}$ element are shown in Figure 7.

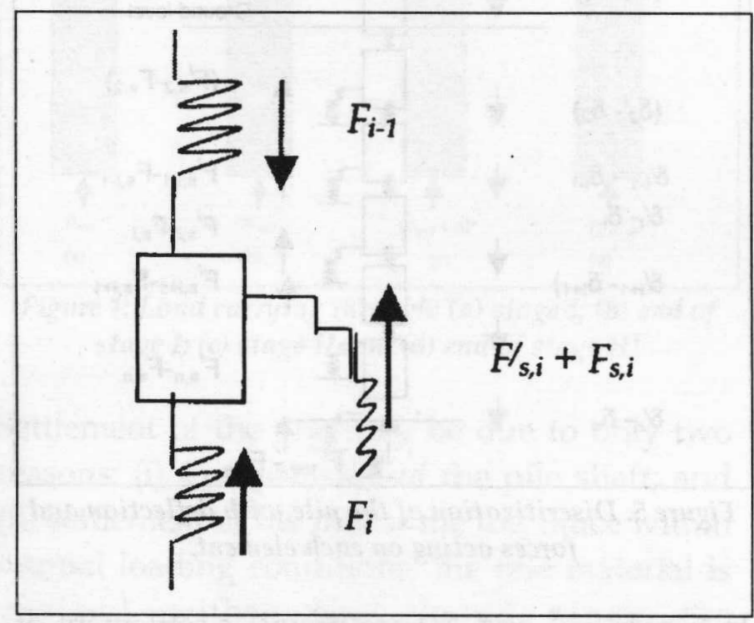

Figure 7: Forces acting on the ith element

Considering the equilibrium of the $\mathrm{i}^{\text {th }}$ element, equilibrium equation given in equation [3] can be written:

$F_{j-1}-F_{j}-F_{s, i}-F_{s, i}=0$

The above equation can be re-written in terms of settlement and spring stiffness as given in Equations (4) and (5): Similarly, $n$ number of equations can be obtained for $n$ number of elements and the stiffness of the $n^{\text {th }}$ pile element, $k_{i}$, should be replaced with the stiffness of the toe spring, $\mathrm{k}_{\text {toe }}$. Considering the above set of equations, following global equilibrium equation [6], can be written in matrix form for the equilibrium of the entire system. The system of equations, given by Equation [6], could be solved to obtain the unknown displacement vector $\{\delta\}$. However, the maximum spring force in the soil spring is $k_{i} Q_{i}$ for the $i^{\text {th }}$ soil spring and $k_{\text {toe }} Q_{\text {toe }}$ for the toe spring. Therefore, special iterative procedure to check and limit the maximum force in the soil springs was adopted in the numerical procedure.

$$
\begin{aligned}
& k_{i-1}\left(\left(\delta_{i-1}^{\prime}+\delta_{i-1}\right)-\left(\delta_{i}^{\prime}+\delta_{i}\right)\right)=k_{i}\left(\left(\delta_{i}^{\prime}+\delta_{i}\right)-\left(\delta_{i+1}^{\prime}+\delta_{i+1}\right)\right)-k_{n t}\left(\delta_{i}^{\prime}+\delta_{i}\right)=0 \\
& \left(k_{i-1}\right) \delta_{i-1}^{\prime}+\left(-k_{i-1}-k_{i}-k_{s i}\right) \delta_{i}^{\prime}+\left(k_{i}\right) \delta_{i+1}^{\prime}+\left(k_{i-1}\right) \delta_{i-1}+\left(-k_{i-1}-k_{i}-k_{s i}\right) \delta_{i}+\left(k_{i}\right) \delta_{i+1}=0 \\
& {[A]\left\{\delta^{\prime}\right\}+[B]\{\delta\}=\{F\}}
\end{aligned}
$$

A Microsoft Excel worksheet was developed to implement the above described numerical procedure. The developed program is capable of dividing the pile into 50 elements and simulating the loading stage of the pile during static load testing.

\subsection{Investigation of the behavior of the piles using the numerical simulation}

The developed simulation program was used to investigate the behavior of the three categories of piles identified in section 3.0. The simulation was done using a $20 \mathrm{~m}$ long, $800 \mathrm{~mm}$ diameter pile in a three layer medium as shown in Figure 8.

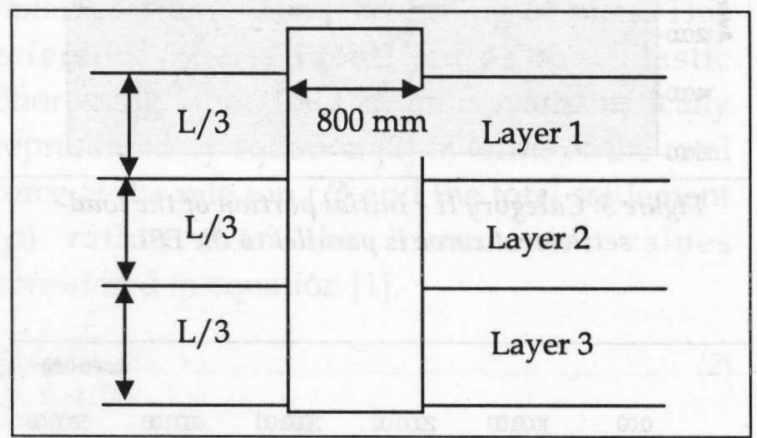

Figure 8: Pile and the subsurface layering used for the numerical simulation

The ultimate end bearing capacity of the pile, skin friction capacity, Young's modulus of the pile material are assumed to be $7037 \mathrm{kN}$, $4021 \mathrm{kN}$ and $35000000 \mathrm{kPa}$ respectively. The skin quakes of the three layers are assumed to be $1 \mathrm{~mm}$ and the toe quake is assumed to be $8 \mathrm{~mm}$ as the base line parameters. The parametric study was carried out as given below.

\subsection{Effect of the location of skin friction on the load-settlement curve}

To investigate the effects of the location of the skin friction on the load-settlement curve, the location of the skin friction along the shaft varied while keeping all the other parameters constant. Three cases were studied by assigning 
the skin friction of $4021 \mathrm{kN}$ to three layers. The resulting load-settlement curves are as given in Figure 9 . Figure 10 is generated by carrying out the same study for the end quake of $16 \mathrm{~mm}$.

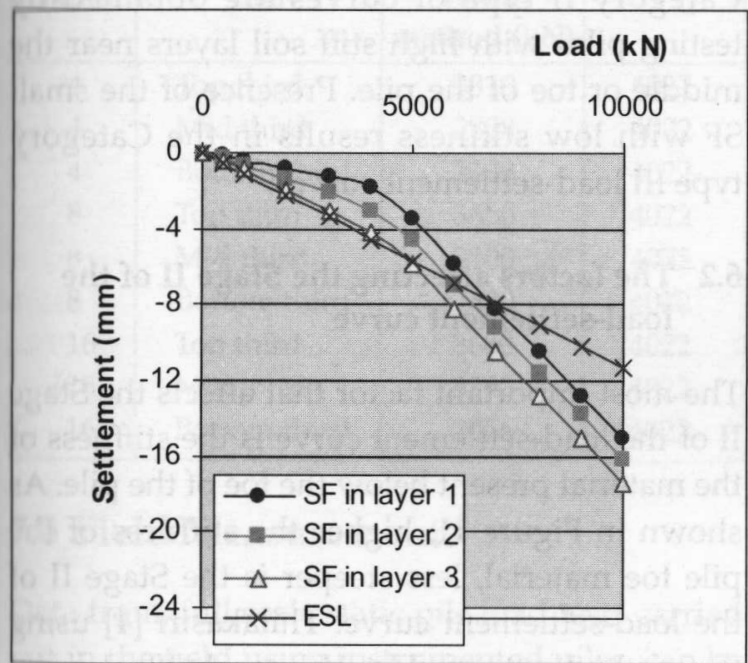

Figure 9: Effect of the location of the SF on the loadsettlement curve (End quake $8 \mathrm{~mm}$ )

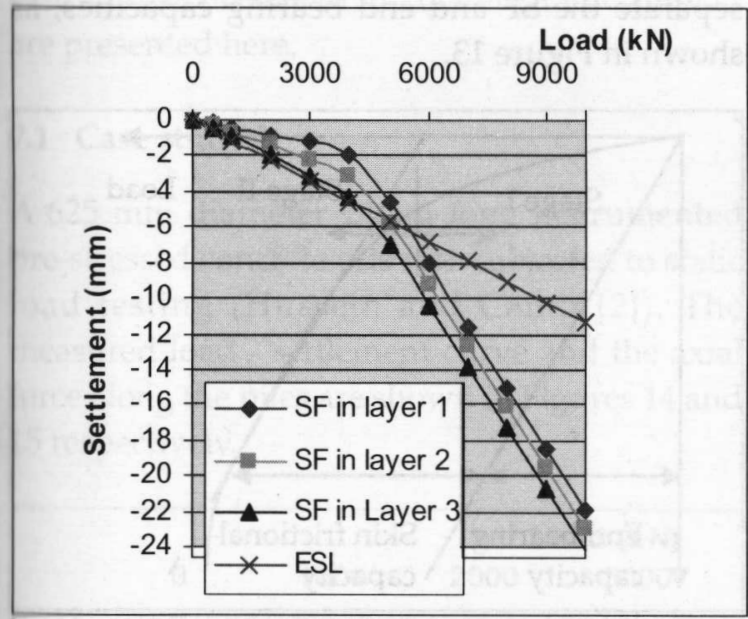

Figure 10: Effect of the location of the SF on the load-settlement curve baseline material parameters (End quake $10 \mathrm{~mm}$ ).

It is evident from the load-settlement curves shown in Figures 9 and 10 that the location of the skin friction along the shaft has a significant effect on the relative location of the loadsettlement curve with respect to the ESL. Presence of the SF near the top of the pile makes the initial portion of the load-settlement curve flatter and as the SF is located in deeper layers load-settlement curve becomes steeper.

\subsection{Effect of the stiffness of the end bearing layer on the load-settlement curve}

The effect of the stiffness of the end bearing layer on the load-settlement curve was investigated by changing the quake of the end bearing layer to $4 \mathrm{~mm}$ and $16 \mathrm{~mm}$ while keeping all the other base parameters unchanged. The stiffness of the bottom spring is estimated as the ratio between the ultimate end bearing capacity and the end quake. Therefore, halving the end quake means doubling the end stiffness and vice versa. The SF was applied at the layer 1 for all three cases. The effect of the changing the stiffness of the end bearing layer on the loadsettlement curve is shown in Figure 11.

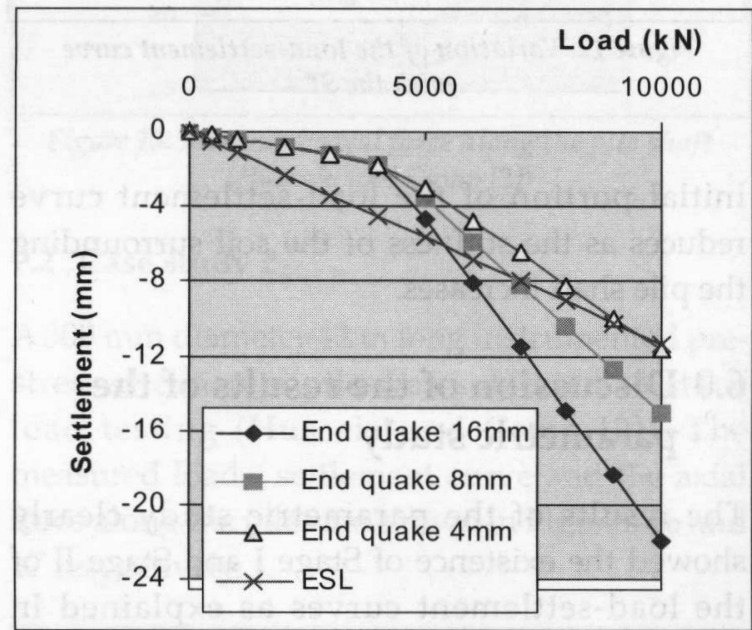

Figure 11: Effects of the changing the stiffness of the end bearing layer on the load-settlement curve.

There is a very minor reduction of the slope of the Stage I of the load-settlement curve as the stiffness of the end bearing layer increases. It doesn't have a significant effect on the loadsettlement curve. However, as the stiffness of the end bearing layer increases the end portion of the load-settlement curve becomes flatter as expected.

\subsection{Effect of the magnitude of the SF on the load-settlement curve}

Effects of magnitude of the SF is investigated by changing the SF to $2011 \mathrm{kN}$ and $8044 \mathrm{kN}$ while keeping all the other base parameters same and applying the SF to the top most layer. The load settlement curves for the three cases are as shown in Figure 12.

It is clear from the variation shown in Figure 12. that the extent of the initial flat region of the load-settlement curve depends on the magnitude of the skin friction. The quake of the SF was kept constant and therefore, the stiffness of the material surrounding the pile shaft increases with the SF. As a result, the slope of the 


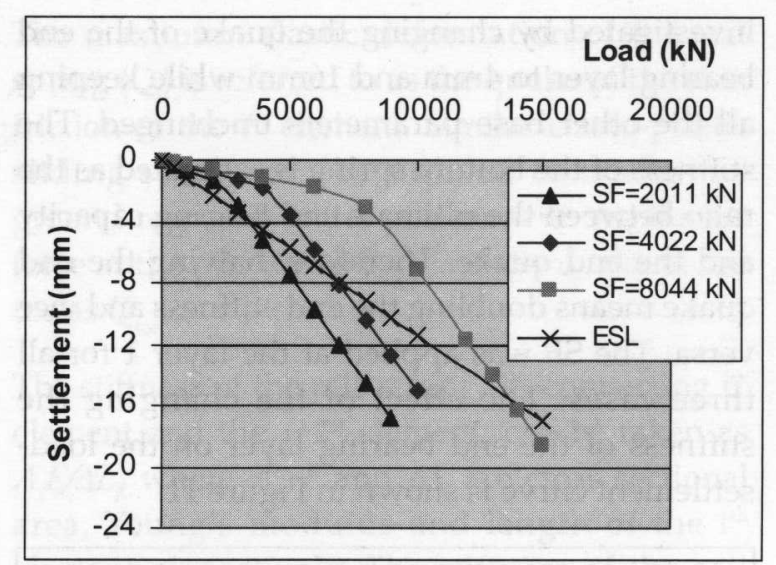

Figure 12: Variation of the load-settlement curve with the SF.

initial portion of the load-settlement curve reduces as the stiffness of the soil surrounding the pile shaft increases.

\subsection{Discussion of the results of the parametric study}

The results of the parametric study clearly showed the existence of Stage I and Stage II of the load-settlement curves as explained in section 2.0. The results of the parametric study can be discussed under two sections: (i) the factors affecting the Stage I of the loadsettlement curve; and (ii) the factors affecting the Stage II of the load-settlement curve.

\subsection{The factors affecting the Stage I of the load-settlement curve}

The load-settlement curves shown in Figures 9 and 10 clearly showed that the stage I of the load-settlement curve is affected by the location of the SF. Presence of the SF near the top of the pile makes the Stage I of the load-settlement curve flatter and the slope of the initial portion of the load-settlement curve becomes steeper, when the SF is acting on the lower levels of the pile. Figure 12 shows that the shear stiffness of the SF affects the slope of the Stage I of the loadsettlement curve. As the shear stiffness of the layer providing SF increases, the slope of the Stage I of the load-settlement curve decreases as shown in Figure 12. Figure 12 also shows that the extent of the Stage I of the load-settlement curve depends on the magnitude of the loadsettlement curve. Moreover, it is evident from the Figure 11 that the magnitude of the end bearing and stiffness of end bearing do not significantly affect the Stage I of the load- settlement curve as stated earlier. Therefore, Category I type load-settlement curves are resulted from the presence of the soil layer with high shear stiffness near the top of the pile. Category II type of curves are obtained by testing piles with high stiff soil layers near the middle or toe of the pile. Presence of the small SF with low stiffness results in the Category type III load-settlement curves.

\subsection{The factors affecting the Stage II of the load-settlement curve}

The most important factor that affects the Stage II of the load-settlement curve is the stiffness of the material present below the toe of the pile. As shown in Figure 11, higher the stiffness of the pile toe material, less steeper is the Stage II of the load-settlement curve. Thilakasiri [4] using the method proposed by Van weele [8] showed that the tangent line drawn to the second stage of the load-settlement curve can be used to separate the SF and end bearing capacities, as shown in Figure 13.

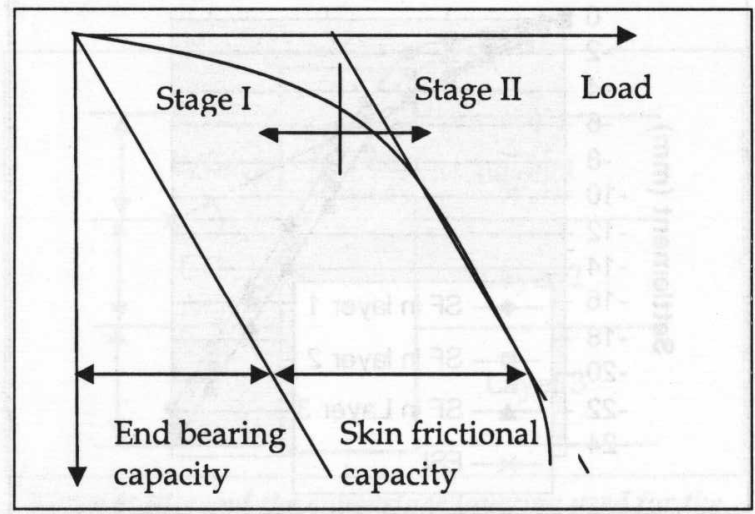

Figure 13: Estimation of the SF and end bearing capacities (Van Weele [8])

If the Van Weele [8] method is applied to the three Load-settlement curves give in Figures 9 and 10, for presence of SF at different locations along the pile shaft, the SF estimated varies as given in Table 1 . Together with the actual SF. Similar variation could be observed for other end stiffness as shown in Table 1.

It is seen from the SF values given in Table 1 that the estimated SF from Van Weele [8] method underestimates the SF when the shear stiffness of the SF layer reduces or when the SF is present at deeper levels of the pile. Moreover, as the stiffness of the end bearing layer reduces, the SF estimated from Van Weele [8] methods deviates more from the actual SF. 
Table 1: SF estimated from Van Weele [8] method for different end stiffness of piles

\begin{tabular}{|c|l|c|c|}
\hline $\begin{array}{c}\text { End } \\
\text { quake } \\
\text { (mm) }\end{array}$ & $\begin{array}{c}\text { Location of SF } \\
\text { along the pile } \\
\text { shaft }\end{array}$ & $\begin{array}{c}\text { SF estimated } \\
\text { from Van } \\
\text { Weele } \\
\text { method (kN) }\end{array}$ & $\begin{array}{c}\text { Actual SF } \\
\text { (kN) }\end{array}$ \\
\hline 4 & Top third & 3310 & 4022 \\
4 & Mid third & 2828 & 4022 \\
4 & Bottom third & 2138 & 4022 \\
8 & Top third & 3650 & 4022 \\
8 & Mid third & 3100 & 4022 \\
8 & Bottom third & 2600 & 4022 \\
16 & Top third & 3680 & 4022 \\
16 & Mid third & 3393 & 4022 \\
16 & Bottom third & 3056 & 4022 \\
\hline
\end{tabular}

\subsection{Field Measurements}

Data from, full scale static pile load tests carried out in the field using instrumented piles, can be used to strengthen the above explained variătions of the load - settlement curves. Two case studies presented in Hussein and Camp(2 ( are presented here.

\subsection{Case study I}

A $625 \mathrm{~mm}$ diameter $24.1 \mathrm{~m}$ long instrumented pre-stressed concrete pile was subjected to static load testing (Hussein and Camp [2]). The measured load - settlement curve and the axial force along the piles are shown in Figures 14 and 15 respectively.

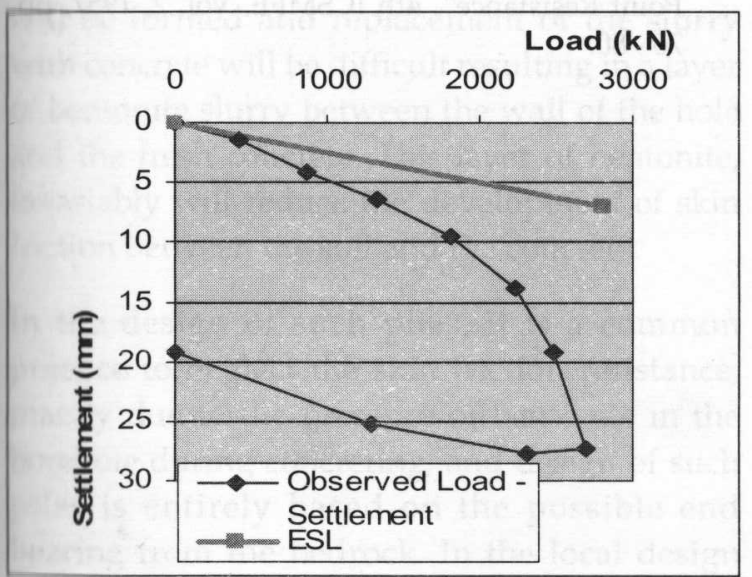

Figure 14: Load-settlement curve (Hussein and Camp [2])

Measured axial force along the pile shaft clearly indicates that the skin friction acting at the pile is almost zero at the top portion of the pile as there is no appreciable reduction in the measured axial force with depth. The load settlement curve shown in Figure 14 is below the ESL and the pile belongs to Category III as shown by the parametric study.

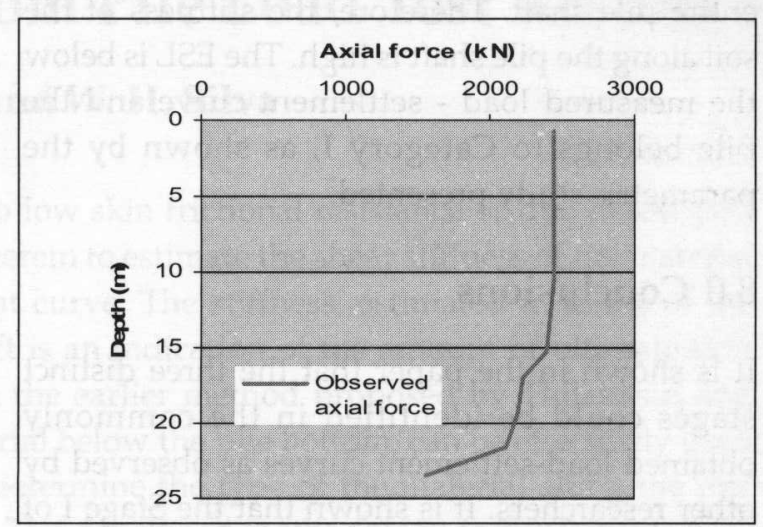

Figure 15: Measured axial force along the pile shaft (Hussein and Camp [2])

\subsection{Case study 2}

A $300 \mathrm{~mm}$ diameter $42 \mathrm{~m}$ long instrumented prestressed concrete pile was subjected to static load testing (Hussein and Camp [2]). The measured load - settlement curve and the axial force along the piles are shown in Figures 16 and 17 respectively.

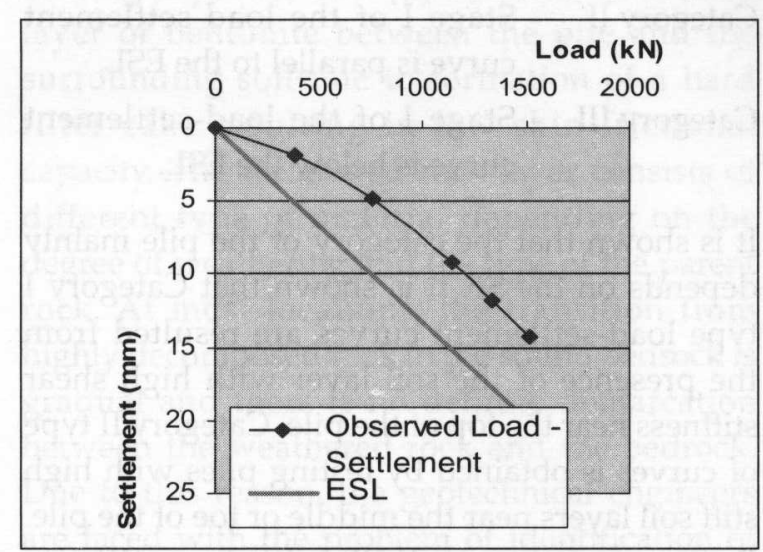

Figure 16: Load-settlement curve (Hussein and Camp [2])

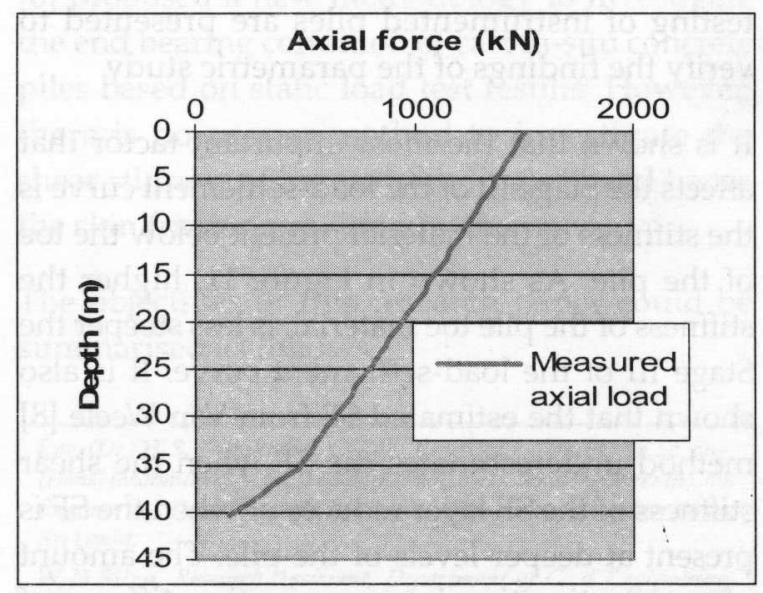

Figure 17: Measured axial force along the pile shaft (Hussein and Camp[2]) 
Measured axial force clearly indicates that a considerable skin friction is developed along the entire pile shaft. Therefore, the stiffness of the soil along the pile shaft is high. The ESL is below the measured load - settlement curve and the pile belongs to Category I, as shown by the parametric study presented.

\subsection{Conclusions}

It is shown in the paper that the three distinct stages could be identified in the commonly obtained load-settlement curves as observed by other researchers. It is shown that the Stage I of the load-settlement curve depends mainly on the skin friction developed and the Stage II depends mainly on the end bearing. The importance of the Elastic Shortening Line (ESL) of the tested pile is highlighted and the field load-settlement curves are categorized into 3 groups, as given below, based on the position of it with respect to the ESL.

\section{Category I - Stage I of the Load-settlement curve is above the ESL. \\ Category II - Stage I of the load-settlement curve is parallel to the ESL. \\ Category III - Stage I of the load-settlement curve is below the ESL.}

It is shown that the category of the pile mainly depends on the SF. It is shown that Category I type load-settlement curves are resulted from the presence of the soil layer with high shear stiffness near the top of the pile. Category II type of curves is obtained by testing piles with high stiff soil layers near the middle or toe of the pile. Presence of the small SF with low stiffness results in the Category type III load-settlement curves. Two case studies of the results of load testing of instrumented piles are presented to verify the findings of the parametric study.

It is shown that the most important factor that affects the Stage III of the load-settlement curve is the stiffness of the material present below the toe of the pile. As shown in Figure 11, higher the stiffness of the pile toe material, is less steeper the Stage III of the load-settlement curve. It is also shown that the estimated SF from Van Weele [8] method underestimates the SF when the shear stiffness of the SF layer reduces or when the SF is present at deeper levels of the pile. The amount of underestimation increases as the stiffness of the end bearing layer increases.

\section{References}

1. Bowels, J. E., "Foundation Analysis and Design", 5th Edition, McGraw-Hill, 1996.

2 Hussein, M. M., and Camp, W., "Dynamic and static tests on driven and cast in-place piles", International Conference on Design and Construction of Deep Foundations, Orlando Florida, USA, 1994, pp 1103 - 1117.

3. Tomlinson, M. J., Pile Design and Construction Practice, 4th Edition, E \& FN Spon, 1994.

4. Thilakasiri, H. S., "A Review of the Design Practices of Bored and Cast In-situ Piles in Sri Lanka", Proceedings of Annual sessions of Institution of Engineers- 2006, Sri Lanka.

5. Thilakasiri, H. S. and Silva, W. H., "Interpretation of Compressibility Properties of Soil Surrounding Bored Piles from Pile Load Test Results", paper submitted for the Annual Sessions of The Institution of Engineers Sri Lanka, 2007(a)

6. Thilakasiri, H. S. and Silva, W. H., "Interpretation of the End Bearing Condition of Bored and Cast In-situ Concrete Piles using Static Pile Load Test Results" accepted for publication in the Proceedings of the Asian Regional Conference of Soil Mechanics and Geotechnical Engineering, December 2007(b), Kolkata.

7. Thilakasiri, H. S., "Analysis of the load settlement curves obtained from static load testing of bored and cast in-situ concrete piles in Sri Lanka", paper accepted for the International Conference on Soil and Rock Engineering, August 2007(c), Colombo, Sri Lanka.

8. Van Weele, A. A., "A Method of Separating the Bearing Capacity of a Pile into Skin-Friction and Point Resistance", 4th ICSMFE, Vol. 2, 1957, pp. $76-80$. 